\title{
Editorial
}

\section{Prenidal aneurysm rupture with posterior fossa AVMs}

Adib A. Abla, M.D., and Michael T. Lawton, M.D.

Department of Neurological Surgery, University of California, San Francisco, California

Patients with cerebellar arteriovenous malformations (AVMs) are significantly more likely to present with hemorrhage than patients with cerebral AVMs, but the explanation is unclear. ${ }^{2}$ In a series of 9 patients presenting with ruptured prenidal aneurysms associated with posterior fossa AVMs, Kouznetsov et al. found that the proportion of patients presenting with hemorrhage was $88 \%$ in their 25 cases of infratentorial AVMs and $51 \%$ in their 208 cases of supratentorial AVMs. ${ }^{7}$ Furthermore, they found that the proportion of patients with ruptured prenidal aneurysms was much higher with infratentorial AVMs than with supratentorial AVMs: $41 \%$ versus $4.7 \%$ ( $p<0.01$ ). The authors suggest that prenidal aneurysms may explain increased bleeding from posterior fossa AVMs.

The UCSF Brain AVM Study Project has explored these relationships previously with similar findings. ${ }^{6}$ Prenidal aneurysms may be one obvious answer, and we also found that nidal or prenidal aneurysms are predictive of a more debilitated presentation with AVM hemorrhage. ${ }^{1}$ However, deep venous drainage is associated with increased rupture risk ${ }^{12}$ and was significantly increased in our cerebellar AVMs. ${ }^{10}$ Small nidus size is also associated with increased rupture risk, ${ }^{11}$ but there were no significant differences in size between cerebellar and cerebral AVMs. ${ }^{10}$ Cerebellar AVMs are less likely to be located in eloquent brain and to be supplied by deep perforating vessels, ${ }^{10}$ but these factors are not associated with AVM rupture. ${ }^{4}$ The difference in hemorrhage rates between cerebellar and cerebral AVMs may simply be explained by the absence of seizures in patients with cerebellar AVMs. Overall, $23 \%$ of our patients with cerebral AVMs presented with seizures, which approximated the difference in hemorrhagic presentation between patients with cerebellar and cerebral AVMs in our AVM cohort ${ }^{10}$ and in the cases described by Kouznetsov et al.

We have struggled to understand why prenidal aneurysms are associated with infratentorial AVMs more than with supratentorial AVMs. Are there differences in underlying hemodynamics in the posterior circulation? Are arterial walls thinner and more fragile in the posterior fossa? Are there differences in curvature and tortuosity that produce more turbulence and erosive flow patterns?
Our efforts to answer these questions with computational fluid dynamics, histopathology, and molecular analysis have been unsuccessful. All that can be said is that these prenidal aneurysms are distally located, have nonsaccular morphology, and are unlike the aneurysms seen in the absence of AVMs. This unusual spike in aneurysm incidence remains an enigma that could lead to experimental aneurysm models and insights into aneurysm pathogenesis.

The current study, like all other such studies, does not offer significant insight into the natural history of prenidal aneurysms..$^{3,5,7-9}$ They are frequently found in patients presenting with hemorrhage, but most studies do not quantify the total number of patients with prenidal aneurysms or the duration of observation. Therefore, it is unclear that unruptured prenidal aneurysms are more dangerous than ordinary saccular aneurysms. It seems safe to conclude, however, that ruptured prenidal aneurysms are, in fact, quite dangerous and require urgent treatment. The authors of the current study preferred endovascular techniques over microsurgery, treating 7 aneurysms with parent artery sacrifice and 2 aneurysms with coiling. ${ }^{7}$ This management speaks to the inaccessibility of some of these aneurysms and their morphological complexity, but it also demonstrates that deconstructive therapies, even when directed to arteries feeding AVMs, can result in ischemic complications, which were seen in 2 patients with vermian strokes. Microsurgical techniques are more likely to preserve flow in the parent artery and can often be incorporated into the AVM resection. Although the exact locations of the aneurysms in this experience were not detailed, excellent exposures exist for posterior inferior cerebellar artery (PICA) and superior cerebellar artery (SCA) aneurysms, and numerous bypass options are available.

Although an appropriately aggressive posture was exhibited toward prenidal aneurysm management in the current study by Kouznetsov et al., a conservative posture was exhibited toward AVM management, with resection deferred in 3 cases (1, 5, and 20 months after hemorrhage) and AVMs untreated in 6 cases. ${ }^{7}$ Of the untreated AVMs, 4 were in the superior vermis, 2 were superficially located in the hemisphere, and all were small in size, giving most of these AVMs low Spetzler-Martin grades with acceptable surgical risks. Our management posture with posterior fossa AVMs is more aggressive for several reasons. First, deep venous drainage, deep location, and hemorrhagic presentation are significant predictors of AVM rupture, making the natural history of posterior fossa AVMs more malignant. ${ }^{12}$ Second, although hematomas associated with infratentorial AVM bleeding are smaller than those associated with supratentorial AVM bleeding, they are poorly tolerated and produce greater neurological devastation. ${ }^{1}$ 
Third, in large part because of their propensity for hemorrhage, infratentorial AVMs are associated with worse outcomes than supratentorial AVMs at late follow-up. ${ }^{10}$ Therefore, we favor proactive management designed to protect against AVM hemorrhage. The cerebellar AVMs described in this report have established anatomical subtypes, good surgical approaches, well-described resection strategies, and excellent outcomes associated with microsurgical resection. ${ }^{10}$ Therefore, we think these patients warrant consideration for surgery and also consideration for aneurysm therapy that excludes the aneurysm simultaneously without sacrificing the parent artery. When the latter objective is not possible or would require substantial modification of the operation, the prenidal aneurysm can be embolized preoperatively.

Finally, it is also important to remember to treat unruptured AVM-associated aneurysms when the AVM is not treated, as with high-grade AVMs deemed too risky for surgery. The risk-benefit relationship is more favorable for these AVM-associated aneurysms than for the AVM itself. The current study does not address the issue of an untreated, unruptured prenidal aneurysm after the AVM has been resected completely. These aneurysms have been reported to regress, but this is uncommon in our anecdotal experience. We therefore recommend vigilant surveillance of untreated, unruptured prenidal aneurysms after curative AVM resection, reserving treatment for those that demonstrate enlargement radiographically over time. (http://thejns.org/doi/abs/10.3171/2014.6.FOCUS14380)

\section{Disclosure}

The authors report no conflict of interest.

\section{References}

1. Abla AA, Nelson J, Rutledge WC, Young WL, Kim H, Lawton MT: The natural history of AVM hemorrhage in the posterior fossa: comparison of hematoma volumes and neurological outcomes in patients with ruptured infra- and supratentorial AVMs. Neurosurg Focus 37(3):E6, 2014

2. Arnaout OM, Gross BA, Eddleman CS, Bendok BR, Getch
CC, Batjer HH: Posterior fossa arteriovenous malformations. Neurosurg Focus 26(5):E12, 2009

3. Brown Jr RD, Wiebers DO, Forbes GS: Unruptured intracranial aneurysms and arteriovenous malformations: frequency of intracranial hemorrhage and relationship of lesions. J Neurosurg 73:859-863, 1990

4. Du R, Keyoung HM, Dowd CF, Young WL, Lawton MT: The effects of diffuseness and deep perforating artery supply on outcomes after microsurgical resection of brain arteriovenous malformations. Neurosurgery 60:638-648, 2007

5. Elhammady MS, Aziz-Sultan MA, Heros RC: The management of cerebral arteriovenous malformations associated with aneurysms. World Neurosurg 80:e123-e129, 2013 (Letter)

6. Kim EJ, Halim AX, Dowd CF, Lawton MT, Singh V, Bennett $\mathrm{J}$, et al: The relationship of coexisting extranidal aneurysms to intracranial hemorrhage in patients harboring brain arteriovenous malformations. Neurosurgery 54:1349-1358, 2004

7. Kouznetsov E, Weill A, Ghostine JS, Gentric JC, Raymond J, Roy D: Association between posterior fossa arteriovenous malformations and prenidal aneurysm rupture: potential impact on management. Neurosurg Focus 37(3):E4, 2014

8. Lv X, Li Y, Yang X, Jiang C, Wu Z: Characteristics of arteriovenous malformations associated with cerebral aneurysms. World Neurosurg 76:288-291, 2011

9. Meisel HJ, Mansmann U, Alvarez H, Rodesch G, Brock M, Lasjaunias P: Cerebral arteriovenous malformations and associated aneurysms: analysis of 305 cases from a series of 662 patients. Neurosurgery 46:793-802, 2000

10. Rodríguez-Hernández A, Kim H, Pourmohamad T, Young WL, Lawton MT: Cerebellar arteriovenous malformations: anatomic subtypes, surgical results, and increased predictive accuracy of the supplementary grading system. Neurosurgery 71:1111-1124, 2012

11. Spetzler RF, Hargraves RW, McCormick PW, Zabramski JM, Flom RA, Zimmerman RS: Relationship of perfusion pressure and size to risk of hemorrhage from arteriovenous malformations. J Neurosurg 76:918-923, 1992

12. Stapf C, Mast H, Sciacca RR, Choi JH, Khaw AV, Connolly ES, et al: Predictors of hemorrhage in patients with untreated brain arteriovenous malformation. Neurology 66:1350-1355, 2006

Please include this information when citing this paper: DOI: 10.3171/2014.6.FOCUS14380. 